\title{
DEVELOPMENT AND CHARACTERIZATION OF ORAL SWELLABLE RAPID RELEASE FILM WITH SUPERDISINTEGRANT-SURFACTANT
}

\author{
NEHA IMTIAZ1* ${ }^{*}$, SUTAPA BISWAS MAJEE ${ }^{2}$, GOPA ROY BISWAS ${ }^{3}$ \\ ${ }^{1 *}$ School of Pharmaceutical Technology, Adamas University, Barasat-Barrackpore Road, P. O.-Jagannathpur, Kolkata 700126, West Bengal, \\ ${ }^{2}$ Department of Pharmacy, NSHM Knowledge Campus, Kolkata-Group of Institutions, 124, B L Saha Road, Kolkata 700053, West Bengal, \\ ${ }^{3}$ Department of Pharmaceutics, Guru Nanak Institute of Pharmaceutical Science and Technology, 147F, Nilgunj Road, Shahid Colony, \\ Panihati, Kolkata 700110, West Bengal \\ "Email: neha11imtiaz@gmail.com
}

Received: 15 Sep 2020, Revised and Accepted: 17 Nov 2020

\begin{abstract}
Objective: Oral disintegrating films consisting of hydrophilic polymer are designed to be quickly hydrated by saliva, adhere to the mucosa and disintegrate rapidly to release the drug. The aim of the present study was to prepare stable, flexible swellable rapid release oral films with hydroxypropyl methylcellulose E15 LV (HPMC) and polyvinyl alcohol (PVA) in different ratios. Guar gum was incorporated as the mucoadhesive agent. In order to achieve rapid disintegration of the film cross carmellose sodium (superdisintegrant) and surfactant like Tween 80 were added. The model drug used in the study was diclofenac sodium.
\end{abstract}

Methods: Films were developed using HPMC E15 LV and PVA by solvent casting method and characterized for thickness, swelling index, disintegration time, folding endurance, drug content, and in vitro drug release pattern and kinetics.

Results: The prepared swellable rapid release oral films were quite flexible and transparent with a smooth texture. The swelling index study confirmed that the films possessed the desired swelling property. Fastest disintegration was observed with the oral film containing HPMC: PVA in the ratio of $2: 1$, guar gum at $120 \mathrm{mg}, 20 \% \mathrm{w} / \mathrm{w}$ crosscarmellose sodium and $4 \% \mathrm{w} / \mathrm{w}$ Tween 80 . The swellable rapid release oral films were found to follow either Higuchi or Korsmeyer-Peppas model with drug release following either Fickian or non-Fickian diffusion. Maximum drug release of around $70 \%$ was observed from the above-mentioned film in $1 \mathrm{hr}$ in simulated salivary fluid.

Conclusion: Therefore, swellable rapid release oral films with HPMC E15 LV: PVA, guar gum, croscarmellose sodium and Tween 80 demonstrated satisfactory swelling, rapid disintegration and improved drug release for oromucosal absorption.

Keywords: HPMC E15 LV, PVA, Guar gum, Crosscarmellose sodium, Swelling index, Oral rapidly swellable disintegrating film

(C) 2021 The Authors. Published by Innovare Academic Sciences Pvt Ltd. This is an open access article under the CC BY license (https://creativecommons.org/licenses/by/4.0/) DOI: https://dx.doi.org/10.22159/ijcpr.2021v13i1.40821. Journal homepage: https://innovareacademics.in/journals/index.php/ijcpr

\section{INTRODUCTION}

Attempts towards developing innovative drug delivery systems, ensuring efficacy, safety and patient acceptability led to the development of oral films [1]. Their improved systemic bioavailability results from bypassing first-pass effect and better permeability due to a well-supplied vascular and lymphatic drainage in the oral mucosa [2]. These films are taken without water due to their ability to disintegrate within a few seconds releasing medication in oral mucosa for absorption and thus can be used for dysphasic and schizophrenic patients. Oral films are found to be satisfactory in many situations like allergic conditions, cold and cough, sore throat, nausea, pain, mouth ulcers, CNS disorders and CVS disorders [3]. They can be broadly classified as mucoadhesive and non-mucoadhesive oral films. Oral mucoadhesive films can be further classified as and swellable sustained-release films. Nonmucoadhesive oral films consist of orodispersible films.

Swellable rapid release films are prepared by using swellable polymers like hydroxypropylmethylcellulose, sodium carboxymethylcellulose, polyethylene oxide, pectin, alginate, xanthan gum. Bhikshapathi et al. [4] reported that films prepared with hydroxypropyl methylcellulose (HPMC) and polyvinyl alcohol (PVA) were quite flexible with the desired peelability. Systems consisting of these polymers absorb a significant amount of water to form a gel. As dissolution medium or biological fluid penetrates the film matrix, swelling is initiated and drug molecules begin to move out of the film by diffusion. In order to facilitate the faster onset of swelling in the mouth, there is a need to accelerate saliva secretion. This can be achieved by incorporating saliva stimulating agents in the formulation. Generally, acids which are used in the preparation of food can be utilized as salivary stimulants, e. g, citric acid, malic acid, lactic acid, ascorbic acid and tartaric acid etc. Among these, citric acid is most preferred saliva stimulating agent in the formulation. Faster disintegration of the film can be attained by using superdisintegrants like sodium starch glycolate, cross carmellose sodium, cross povidone to promote the faster release of drug. Sarangi et al. [5] reported that films prepared with $20 \% \mathrm{w} / \mathrm{w}$ superdisintegrant demonstrated faster disintegration of the films. Gum is added in the oral film formulation, promotes adhesion to the mucosal surface and prevents swallowing of swollen film on administration. The prepared film therefore, is designed to swell rapidly, stick/adhere to the oral mucosa for rapid disintegration to occur to release the drug, which is absorbed by bypassing hepatic first-pass metabolism.

In the present study oral swellable rapid release films of diclofenac sodium were prepared using HPMC E15 LV, PVA and guar gum. Other excipients like cross carmellose sodium, citric acid and Tween 80 were incorporated for their superdisintegrant, saliva stimulating and wetting effects, respectively. The ultimate goal of the study was to develop oral films with rapid swelling and disintegration properties to ensure fast release of drug and rapid onset of action when placed in oral mucosa.

No other previous studies have developed swellable rapid release oral films by employing superdisintegrant, surfactant and saliva stimulating agent simultaneously in the formulation.

\section{MATERIALS AND METHODS}

\section{Material}

Hydroxypropylmethylcellulose E15 LV was purchased from Loba Chemie Pvt. Ltd, polyvinyl alcohol from Merck and Co., guar gum from Akshar Exim Company Pvd. Ltd, dibutyl phthalate from 
Chemicorp Specialties India Private Limited, citric acid and cross carmellose sodium (CCS) from Loba Chemie Pvd. Ltd. Diclofenac sodium was obtained as a gift from Martina Biogenics Pvt. Ltd. All other solvents and chemicals were of analytical grade.

\section{Preparation of the oral swellable rapid release film}

Oral swellable rapid release films were prepared by solvent casting method. Drug was dissolved in water and all other ingredients (HPMC E15 LV, PVA, guar gum, dibutyl phthalate and Tween 80) were added one by one in the sequence mentioned, stirred for $1 \mathrm{~h}$, which was kept aside to remove all the air bubble entrapped. Then citric acid and cross carmellose sodium were added and stirred for 1 h. The solution was allowed to stand for $30 \mathrm{~min}$ for deaeration to occur. The solution was casted on a glass plate and dried at room temperature for $24 \mathrm{~h}$. Then the dried films were peeled off from the glass plate, cut into appropriate sizes, and stored in a desiccator until use.
Various formulations were prepared by changing the amount of superdisintegrant $(5,10,15$ and $20 \% \mathrm{w} / \mathrm{w})$ at the same ratio of HPMC: PVA (D1-D4 formulations), changing the amount of gum (120 $\mathrm{mg}$ and $180 \mathrm{mg}$ ) at 3 different ratios of HPMC: PVA (1:1, 1:2 and 2:1) and keeping superdisintegrant at $20 \% \mathrm{w} / \mathrm{w}$ (GA1-GB3 formulations) Eqn(1) and by adding different surfactants $(2 \% \mathrm{w} / \mathrm{w})$ and keeping HPMC: PVA at 2:1, guar gum at $180 \mathrm{mg}$ and superdisintegrant at $20 \% \mathrm{w} / \mathrm{w}$ (T-P formulations). T1-T3 formulations were obtained after observing that among the three surfactants selected for study, the formulations with Tween $80(4 \% \mathrm{w} / \mathrm{w})$ exhibited best possible properties with the films. Different ratios of HPMC E15 LV: PVA were used to find the best ratio, which will give highly flexible films. The amounts of guar gum, superdisintegrant and Tween 80 were adjusted to obtain films having desirable swelling and adhesive property with the rapid disintegrating property. For the purpose of the study, 16 different formulations were developed. Composition of the various formulations are given in table 1.

Table 1: Formulations containing different \% of superdisintegrant, varying ratios of HPMC: PVA, varying amount of gum, different surfactants, varying $\%$ of selected surfactant and drug-loaded formulations

\begin{tabular}{|c|c|c|c|c|c|c|c|c|c|}
\hline Batch & $\begin{array}{l}\text { Drug } \\
\text { (mg) }\end{array}$ & $\begin{array}{l}\text { HPMC E15 LV } \\
\text { (mg) }\end{array}$ & PVA (mg) & $\begin{array}{l}\text { Surfactant } \\
\text { (mg) }\end{array}$ & $\begin{array}{l}\text { Dibutyl } \\
\text { phthalate (mg) }\end{array}$ & $\begin{array}{l}\text { Guar gum } \\
\text { (mg) }\end{array}$ & CCS (mg) & $\begin{array}{l}\text { Citric acid } \\
\text { (mg) }\end{array}$ & $\begin{array}{l}\text { Water } \\
\text { (mg) }\end{array}$ \\
\hline D1 & - & 500 & 500 & - & 5.25 & 180 & 102.26 & 757 & q. s. \\
\hline D2 & - & 500 & 500 & - & 5.25 & 180 & 204.44 & 654.77 & q. $s$. \\
\hline D3 & - & 500 & 500 & - & 5.25 & 180 & 306.67 & 522.54 & q. s. \\
\hline D4 & - & 500 & 500 & - & 5.25 & 180 & 408.89 & 450.32 & q. s. \\
\hline GA1 & - & 500 & 500 & - & 5.25 & 120 & 408.89 & 510.32 & q. s. \\
\hline GB1 & - & 333 & 667 & - & 5.25 & 120 & 408.89 & 510.32 & q. s. \\
\hline GC1 & - & 667 & 333 & - & 5.25 & 120 & 408.89 & 510.32 & q. s. \\
\hline GA2 & - & 500 & 500 & - & 5.25 & 180 & 408.89 & 510.32 & q. s. \\
\hline GB2 & - & 333 & 667 & - & 5.25 & 180 & 408.89 & 510.32 & q. $s$. \\
\hline GC2 & - & 667 & 333 & - & 5.25 & 180 & 408.89 & 510.32 & q. s. \\
\hline $\mathrm{T}$ & - & 667 & 333 & 40.9 & 5.25 & 180 & 408.89 & 469.42 & q. s. \\
\hline S & - & 667 & 333 & 40.9 & 5.25 & 180 & 408.89 & 469.42 & q. $s$. \\
\hline $\mathrm{P}$ & - & 667 & 333 & 40.9 & 5.25 & 180 & 408.89 & 469.42 & q. $s$. \\
\hline $\mathrm{T} 1$ & - & 667 & 333 & 40.9 & 5.25 & 180 & 408.89 & 469.42 & q. $s$. \\
\hline $\mathrm{T} 2$ & - & 667 & 333 & 61.35 & 5.25 & 180 & 408.89 & 448.97 & q. $s$. \\
\hline T3 & - & 667 & 333 & 82 & 5.25 & 180 & 408.89 & 368.32 & q. s. \\
\hline TA1 & - & 500 & 500 & 82 & 5.25 & 120 & 408.89 & 428.32 & q. $s$. \\
\hline TA2 & - & 333 & 667 & 82 & 5.25 & 120 & 408.89 & 428.32 & q. $s$. \\
\hline TA3 & - & 667 & 333 & 82 & 5.25 & 120 & 408.89 & 428.32 & q. s. \\
\hline TB1 & - & 500 & 500 & 82 & 5.25 & 180 & 408.89 & 368.32 & q. s. \\
\hline TB2 & - & 333 & 667 & 82 & 5.25 & 180 & 408.89 & 368.32 & q. $s$. \\
\hline TB3 & - & 667 & 333 & 82 & 5.25 & 180 & 408.89 & 368.32 & q. s. \\
\hline TA D1 & 102.2 & 500 & 500 & 82 & 5.25 & 120 & 408.89 & 266.12 & q. s. \\
\hline TA D2 & 102.2 & 333 & 667 & 82 & 5.25 & 120 & 408.89 & 266.12 & q. $s$. \\
\hline TA D3 & 102.2 & 667 & 333 & 82 & 5.25 & 120 & 408.89 & 266.12 & q. s. \\
\hline TB D1 & 102.2 & 500 & 500 & 82 & 5.25 & 180 & 408.89 & 266.12 & q. $s$. \\
\hline TB D2 & 102.2 & 333 & 667 & 82 & 5.25 & 180 & 408.89 & 266.12 & q. $s$. \\
\hline TB D3 & 102.2 & 667 & 333 & 82 & 5.25 & 180 & 408.89 & 266.12 & q. $s$. \\
\hline
\end{tabular}

\section{Characterization}

\section{Organoleptic characterization}

Formulations were observed visually for their colour, appearance, texture and opacity. Stickiness was checked manually with fingers.

\section{Determination of surface $\mathrm{pH}$}

The surface $\mathrm{pH}$ of the films was determined at room temperature $\left(25^{\circ} \mathrm{C}\right)$. The film to be tested was placed in a petri dish and was moistened with $0.5 \mathrm{ml}$ of distilled water and kept for $1 \mathrm{~min}$. The $\mathrm{pH}$ was noted after bringing the electrode of the $\mathrm{pH}$ meter in contact with the surface of the formulation and allowing equilibration for 1.0 $\mathrm{min}$. The $\mathrm{pH}$ of the formulations was determined using digital $\mathrm{pH}$ meter (Fisher Scientific-Accumet AE 150) [6].

\section{Folding endurance}

Folding endurance was determined by repeated folding of the film at the same place till the strip breaks. The number of times the film is folded without breaking was computed as the folding endurance value [7].

\section{Moisture loss (Water vapor transmission)}

The percent moisture loss was determined by placing the prepared film in desiccators containing anhydrous calcium chloride. The film was taken out after $72 \mathrm{~h}$ and reweighed. The percent moisture loss was calculated using following formula

$$
\% \text { Moisture Loss }=\left[\left(\mathrm{W}_{0}-\mathrm{W}_{\mathrm{t}}\right) / \mathrm{W}_{0}\right] * 100
$$

Where $\mathrm{W}_{0}=$ initial weight, $\mathrm{W}_{\mathrm{t}}=$ final weight [8]

\section{Weight uniformity}

Weight variation was studied by individually weighing randomly selected films and calculating the average weight [9].

\section{Thickness}

The thickness of the patch was measured using digital Vernier Caliper with a least count of $0.01 \mathrm{~mm}[10]$.

\section{Swelling index}

Film swelling studies were conducted using phosphate buffer $(\mathrm{pH}$ 6.8) and water. Weighed film was submerged separately in 
phosphate buffer (pH 6.8) and water. Increase in the weight of film was noted at constant pre-determined time and determination was carried out till two consecutive values became same. Degree of swelling was determined by the formula.

Degree of swelling $=[($ final weight-initial weight $) /$ initial weight $] * 100$

\section{Disintegration time}

Disintegration test was carried out in water and phosphate buffer $(\mathrm{pH} 6.8)$ at a temperature of $37 \pm 0.5^{\circ} \mathrm{C}$. The disintegration test was performed in the USP disintegration time testing apparatus. A portion of film measuring $\left(1 \mathrm{X} 1 \mathrm{~cm}^{2}\right)$ was introduced into each tube of the disintegration apparatus IP. A disc was added into the tube. The assembly was suspended in medium and operated until the film disintegrated [11].

\section{Drug content determination}

Oral films containing drug equivalent to $5 \mathrm{mg}$ was cut from the respective film formulations and were added to phosphate buffer $\mathrm{pH}$ 6.8), which was stirred with a magnetic stirrer for complete leaching of drug. The dispersion was filtered through Whatman filter paper No. 1. An aliquot of filtrate was withdrawn and its absorbance was measured spectrophotometrically at $276 \mathrm{~nm}$ (Shimadzu UV-VIS 1800 spectrophotometer). The drug content of formulations was determined from calibration curve of the drug in the said buffer $[12,13]$.

\section{In vitro drug release studies}

Drug release studies were carried out in $900 \mathrm{ml}$ of phosphate buffer (pH 6.8) in USP Type II apparatus. The medium was equilibrated to the temperature of $37 \pm 0.5{ }^{\circ} \mathrm{C}$. A cut portion of film formulation containing drug equivalent to $40 \mathrm{mg}$ was used for the study. Stirring speed was fixed at $50 \mathrm{rpm}$ and study was continued for $1 \mathrm{~h}$. At definite time intervals, $5 \mathrm{ml}$ of dissolution medium was withdrawn; filtered and replaced with $5 \mathrm{ml}$ of fresh medium to maintain sink conditions. Suitable dilutions of the filtrate were done with dissolution medium and were analyzed spectrophotometrically at $\lambda_{\max }$ of $276 \mathrm{~nm}$ using a UV-vis spectrophotometer. Drug release data were subjected to mathematical modelling by using zero order, first order, Higuchi and Korsmeyer-Peppas models [14].

\section{RESULTS AND DISCUSSION}

HPMC absorbs water rapidly and swells to form a matrix layer due to which HPMC-based drug delivery systems exhibit controlled drug release behaviour $[15,16]$. In order to improve the peelability and to achieve customized drug release from the developed oral swellable rapid release films, HPMC was used in combination with PVA, which is a disintegrating polymer capable of facilitating burst release. Additionally, both HPMC E15 LV and PVA were chosen because of their mucoadhesive nature and biodegradability. In this study, dibutyl phthalate was used as the plasticizer to improve the flow property and strength of the film former [17-18]. Among the various superdisintegrants, crosscarmellose sodium was selected as it rapidly absorbs water and facilitates rapid disintegration of the oral film.

The films prepared were found to be colorless, odourless, smooth in appearance and without any air bubbles. They possessed good peelability and were easily removed from the glass plate without any break. Films having a higher amount of HPMC E15 LV and a higher amount of guar gum showed greater stickiness. Guar gum was capable of imparting the desired adhesion which is required for instant adhesion inside the oral cavity upon administration to avoid the swallowing of the film into the GI tract. Addition of surfactant further enhanced the adhesiveness by improving upon film wettability.

The measured surface $\mathrm{pH}$ of the prepared films was found to be in the range of 6.32 to 6.98 (table 2), indicating that there will not be any kind of irritation to the mucosal lining of the oral cavity. Folding endurance was found to be in the range of 100 to 190 (table 2) and the films were found to be quite flexible. Films having higher amount of HPMC E15 LV had greater folding endurance than those having higher amount of PVA. The prepared formulations showed a moisture loss in the range of 1.22 to 3.205 (table 2), which indicates good physical stability and integrity of the films.

All the prepared films had uniform thickness throughout (table 2). Results of weight variation study showed the uniformity in the formulations. Drug content was found to be in the range $28.19 \%$ to $48.84 \%$ for the prepared films.

Table 2: Results of determination of surface $\mathrm{pH}$, folding endurance, \% moisture loss, thickness and weight uniformity of the prepared swellable rapid release oral films

\begin{tabular}{|c|c|c|c|c|c|}
\hline Formulations & Surface pH & Folding endurance & \%Moisture loss & Thickness (mm) & Weight uniformity (mg) \\
\hline D1 & 6.65 & 150 & 1.37 & 0.06 & 43.80 \\
\hline D2 & 6.79 & 150 & 1.40 & 0.061 & 41.40 \\
\hline D3 & 6.82 & 100 & 1.39 & 0.065 & 41.60 \\
\hline D4 & 6.84 & 100 & 1.44 & 0.0600 & 42.90 \\
\hline GA1 & 6.70 & 115 & 1.88 & 0.050 & 49.61 \\
\hline GB1 & 6.92 & 110 & 1.90 & 0.060 & 56.16 \\
\hline GC1 & 6.83 & 145 & 2.37 & 0.040 & 54.75 \\
\hline GA2 & 6.94 & 182 & 1.50 & 0.050 & 58.23 \\
\hline GB2 & 6.72 & 180 & 1.34 & 0.050 & 52.86 \\
\hline GC2 & 6.45 & 185 & 1.58 & 0.045 & 55.00 \\
\hline $\mathrm{T}$ & 6.61 & 100 & 1.88 & 0.062 & 53.09 \\
\hline$S$ & 6.65 & 180 & 1.26 & 0.040 & 53.00 \\
\hline $\mathrm{P}$ & 6.45 & 140 & 1.22 & 0.050 & 54.00 \\
\hline $\mathrm{T} 1$ & 6.48 & 100 & 1.70 & 0.040 & 50.80 \\
\hline $\mathrm{T} 2$ & 6.56 & 167 & 1.77 & 0.056 & 53.12 \\
\hline T3 & 6.74 & 170 & 2.56 & 0.043 & 52.09 \\
\hline TA1 & 6.82 & 121 & 2.58 & 0.056 & 50.99 \\
\hline TA2 & 6.76 & 119 & 2.39 & 0.040 & 56.74 \\
\hline TA3 & 6.43 & 130 & 2.99 & 0.060 & 54.26 \\
\hline TB1 & 6.67 & 170 & 2.97 & 0.050 & 59.71 \\
\hline TB2 & 6.64 & 125 & 2.77 & 0.058 & 53.06 \\
\hline TB3 & 6.98 & 144 & 3.16 & 0.060 & 56.74 \\
\hline TA D1 & 6.77 & 130 & 2.89 & 0.040 & 53.19 \\
\hline TA D2 & 6.45 & 110 & 2.20 & 0.040 & 53.16 \\
\hline TA D3 & 6.53 & 186 & 2.95 & 0.050 & 49.61 \\
\hline TB D1 & 6.32 & 170 & 2.79 & 0.060 & 52.33 \\
\hline TB D2 & 6.45 & 160 & 2.68 & 0.050 & 53.18 \\
\hline TB D3 & 6.39 & 190 & 3.20 & 0.050 & 50.02 \\
\hline
\end{tabular}


Swelling index for all formulations were found to be greater in phosphate buffer than in water. The parameter was influenced by the amount of gum, HPMC E15 LV: PVA ratio, concentration of superdisintegrant, as well as the presence of surfactant. Increased amount of superdisintegrant resulted in a higher swelling index due to more water absorption (D1-D4). Formulation containing higher amount of HPMC E15 LV exhibited a higher swelling index because the polymer chains of HPMC E15 LV quickly absorb the solvent and swell. Addition of surfactant was found to be useful in increasing the swelling capacity of the films due to its wetting property. Among the surfactants (Tween 80, SLS, Poloxomer 407) used in the study, Tween 80 showed highest increase in swelling index. On increasing the percentage of Tween 80 from $2 \%$ to $4 \% \mathrm{w} / \mathrm{w}$ there was an increase in the swelling index (table 3).
The disintegration times for the films ranged from 5-18 min in phosphate buffer ( $\mathrm{pH}$ 6.8) and 7-20 min in water with those containing $120 \mathrm{mg}$ gum and $4 \% \mathrm{w} / \mathrm{w}$ surfactant showing least disintegration time. It was found that superdisintegrant at $20 \% \mathrm{w} / \mathrm{w}$ was able to cause faster disintegration of the films. Increasing the amount of gum resulted in lower disintegration time. On the contrary, the higher amount of HPMC E15 LV delayed disintegration because HPMC E15 LV forms a viscous gel barrier by rapid solvent uptake thus hindering the film disintegration. Surfactant addition aided in decreasing the disintegration time due to its wetting and solubilizing property. It is thus clear that apart from including superdisintegrant and surfactant, the amount of cellulosic polymer in the film formulation should be adjusted carefully to get the desired rapid disintegration of the film (table 3).

Table 3: Results of determination of swelling index and disintegration time of the swellable rapid release oral films

\begin{tabular}{|c|c|c|c|c|}
\hline \multirow[t]{2}{*}{ Formulations } & Swelling & Index & Disintegration & Time \\
\hline & In water (\%) & In phosphate buffer (pH 6.8) (\%) & In water (min) & In phosphate buffer (pH 6.8) (min) \\
\hline D1 & 92 & 119 & 20 & 18 \\
\hline D2 & 115 & 133 & 19 & 15 \\
\hline D3 & 150 & 167 & 14 & 13 \\
\hline D4 & 160 & 217 & 12 & 10 \\
\hline GA1 & 114 & 156 & 10 & 9 \\
\hline GB1 & 100 & 167 & 12 & 10 \\
\hline GC1 & 185 & 240 & 9 & 8 \\
\hline GA2 & 102 & 120 & 12 & 11 \\
\hline GB2 & 88 & 147 & 16 & 14 \\
\hline GC2 & 135 & 194 & 11 & 10 \\
\hline $\mathrm{T}$ & 93.75 & 114 & 11 & 10 \\
\hline $\mathrm{S}$ & 88 & 102 & 13 & 12 \\
\hline $\mathrm{P}$ & 78.94 & 86 & 15 & 14.5 \\
\hline T1 & 93.75 & 102 & 11 & 10 \\
\hline $\mathrm{T} 2$ & 100 & 120 & 9.2 & 8.5 \\
\hline T3 & 145 & 200 & 8 & 7 \\
\hline TA1 & 166.6 & 269 & 6.34 & 5.25 \\
\hline TA2 & 181 & 193 & 7 & 6.36 \\
\hline TA3 & 320 & 434 & 5.21 & 5 \\
\hline TB1 & 161 & 250 & 8.44 & 7.08 \\
\hline TB2 & 151 & 156 & 8.51 & 7.22 \\
\hline TB3 & 185 & 264.7 & 8.14 & 6.52 \\
\hline TA D1 & 156.6 & 266 & 6.32 & 5.35 \\
\hline TA D2 & 188 & 198 & 7.2 & 6.39 \\
\hline TA D3 & 320 & 440 & 6.21 & 5.02 \\
\hline TB D1 & 165 & 254 & 8.08 & 7.44 \\
\hline TB D2 & 145 & 166 & 8.22 & 7.51 \\
\hline TB D3 & 180.5 & 276.6 & 8.52 & 7.14 \\
\hline
\end{tabular}

Drug content was found to be in the range $28.19 \%$ to $48.84 \%$ for the prepared films.

From the results on in vitro drug release studies of swellable rapid release oral films of diclofenac sodium, it can be said that initial drug release was slow but with time, the release became rapid (table 4). Presence of guar gum, HPMC E15 LV, Tween 80 and citric acid led to rapid uptake of simulated salivary fluid (pH6.8) by the film followed by rapid film disintegration owing to the presence of crosscarmellose sodium and subsequently greater drug release with time (fig. 1). In vitro drug release was found to follow either Korsmeyer-Peppas or Higuchi model indicating the formation of a rapid releasing matrix. Both Fickian and non-Fickian diffusion of the drug were observed depending on the film composition (table 5).

Table 4: Cumulative percent drug (diclofenac sodium) released from swellable rapid release oral film

\begin{tabular}{llllll}
\hline Time (min) & TA D1 & TA D2 & TA D3 & TB D1 & TB D2 \\
\hline 2 & 11.773 & 9.15463 & 8.580613 & 11.5002 & 7.16915 \\
4 & 15.488 & 14.6532 & 9.281383 & 14.1661 & 8.92394 \\
6 & 18.496 & 18.7863 & 12.07663 & 16.4568 & 11.5002 \\
8 & 20.871 & 21.093 & 18.95142 & 23.7326 & 15.2461 \\
9 & 22.063 & 22.253 & 22.75059 & 24.0615 & 15.6279 \\
10 & 22.846 & 22.4378 & 24.55422 & 24.6582 & 18.3283 \\
15 & 38.0622 & 26.4455 & 38.5543 & 28.1363 & 24.7511 \\
20 & 46.777 & 28.993 & 43.89803 & 30.267 & 23.9045 \\
25 & 58.0632 & 34.1885 & 55.53448 & 32.6603 & 24.0211 \\
30 & 62.0385 & 38.4727 & 63.73092 & 35.3783 & 28.7192 \\
60 & 68.2559 & 48.5383 & 69.50435 & 37.7617 & 30.8255 \\
\hline
\end{tabular}




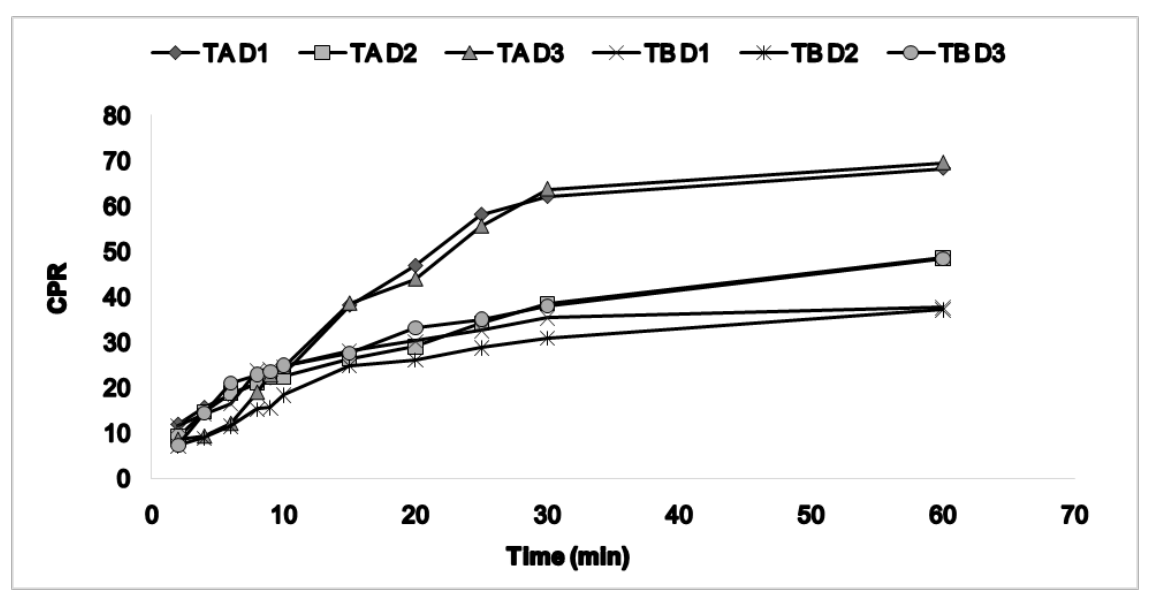

Fig. 1: In vitro drug release profiles of selected oral swellable rapid release films containing diclofenac sodium

Table 5: Modelling of drug release kinetics of swellable rapid release oral film, F=Fickian diffusion, NF=Non-Fickian diffusion, ND=type of diffusion could not be determined, $\mathrm{KP}=$ Korsmeyer-Peppas model)

\begin{tabular}{llllll}
\hline Formulation & Zero-order & First-order & Higuchi & \multicolumn{2}{l}{ Korsmeyer-Peppas } \\
\cline { 2 - 6 } & $\mathbf{R}^{\mathbf{2}}$ & $\mathbf{R}^{\mathbf{2}}$ & $\mathbf{R}^{\mathbf{2}}$ & $\mathbf{R}^{\mathbf{2}}$ & Type of diffusion \\
\hline TA D1 & 0.8086 & 0.7144 & 0.914 & 0.9438 & 0.6114 \\
TA D2 & 0.9042 & 0.7121 & 0.9856 & 0.9831 & 0.4728 \\
TA D3 & 0.8128 & 0.6622 & 0.925 & 0.9199 & 0.325 \\
TB D1 & 0.7078 & 0.5816 & 0.8752 & 0.9305 & 0.3835 \\
TB D2 & 0.8302 & 0.6694 & 0.9533 & 0.9685 & 0.5381 \\
TB D3 & 0.8128 & 0.6622 & 0.9250 & 0.9199 & 0.5201 \\
\hline
\end{tabular}

Among all the formulations, the swellable rapid release oral film consisting of HPMC: PVA at 2:1, 20\% w/w superdisintegrant, $4 \%$ $\mathrm{w} / \mathrm{w}$ Tween 80 and $120 \mathrm{mg}$ guar gum may be regarded as the best formulation as it showed the fastest disintegration $(5 \mathrm{~min}$ in simulated salivary fluid and $5.21 \mathrm{~min}$ in water) and highest drug release (approximately 70\%) in salivary $\mathrm{pH}$.

\section{CONCLUSION}

From the above studies, it can be concluded that oral swellable rapid release films developed from an optimum ratio of HPMC E15 LV and PVA, containing guar gum, Tween 80 as surfactant, citric acid as saliva stimulating agent and crosscarmellose sodium as superdisintegrant can be used for rapid oromucosal absorption bypassing the first-pass metabolism. The best formulation possessed satisfactory organoleptic properties, mechanical strength and demonstrated high swelling index, rapid disintegration and high drug release in salivary $\mathrm{pH}$.

\section{ACKNOWLEDGMENT}

From the inner of my heart, I take this opportunity to express my deep sense of gratitude and respect to my teacher, guide, mentor Dr. Sutapa Biswas Majee, for her professional devotion, intellectual vigor and excellent guidance, interaction with discussion, valuable suggestions, encouragements and imaginative improvements that made a substantial contribution to materialize my project dissertation.

At the same time, I am indebted to our Director, Prof. (Dr.) Subhasis Maity who gave me permission to carry out the work by providing out all the facilities. I am also thankful to our library staff and Bhakta Sir, Chinmay Sir, Shubhankar Sir and the laboratory technicians and laboratory assistance for extending their helping hands throughout the project work.

I am extremely grateful to my parents for their financial support of this project work and also deep appreciation for their indispensable aid, moral support, encouragement and everlasting love.

Finally, I would like to offer my deep sense of gratitude to all the teachers of NSHM College of Pharmaceutical Technology and
Pharmacology and to co-researchers of Pharmaceutical Research Lab. for their co-operation and encouragement throughout my work.

\section{FUNDING}

Nil

\section{AUTHORS CONTRIBUTIONS}

All the authors have contributed equally.

\section{CONFLICT OF INTERESTS}

Declared none

\section{REFERENCES}

1. Arun A, Amrish C, Vijay S, Kamla P. Fast dissolving oral films. An innovative drug delivery system and dosage form. Int J ChemTech Res 2010;2:576-83.

2. Irfan M, Rabel S, Bukhtar Q, Qadir MI, Jabeen F, Khan A. Orally disintegrating films: a modern expansion in drug delivery system. Saudi Pharm J 2016;9:537-46.

3. Malke M, Shidhaye, Kadam VJ. Formulation and evaluation of oxacarbazine fast-dissolving tablets. Indian J Pharm Sci 2007;69:211-4.

4. Jyothi S, DVRN Bhikshapathi. Development and optimization of fast dissolving oral film containing aripiprazole. Int J Pharm Sci Drug Res 2017;9:327-33.

5. Deepak KS, Suman KM, Sanjib KS, Ritesh KD, Rabi NR Formulation and evaluation of fast dissolving oral films containing losartan potassium. Int J Res Pharm Chem 2017;7:470-81.

6. Obermeier T, Kohr K, Kramer KK. Oral quickly disintegrating film, which cannot be spit out for an antiemetic or antimigraine agent U. S. Patent 2008/0213343 A1; 2008.

7. Mcnaughton $F$. The use of ergotamine tartrate in migraine. Canad Med Assoc J 1935;33:664-5.

8. Barnhart SD. Thin-film oral dosage forms in the modified release. Drug Dev Technol 2007;1:34-5.

9. Wale A, Weller PJ. Handbook of pharmaceutical excipients; 1994;2:24, 27, 352, 448. 
10. Arya A, Chandra A. Fast dissolving oral films: an innovative drug delivery system and dosage form. Int J Chemtech Res 2010;2:576-83.

11. Kumar RS, Annu, Kusuma L, Parudhvi R. Design, optimization and evaluation of cetirizine dihydrochloride fast dissolving films employing starch tartrate-a novel superdisintegrant. Int J Curr Pharm Res 2019;11:75-86.

12. Zankahana P, Rahil B, Samir S. Formulation optimization and evaluation of mouth dissolving film of ramosetron hydrochloride. Int J Curr Pharm 2020;12:99-106.

13. Indian Pharmacopoeia: Government of India, Ministry of Health and Family Welfare Department. $7^{\text {th }}$ edition; 2014;1:559-621.
14. Dash S, Murthy PN, Nath L, Chowdhury P. Kinetic modeling on drug release from controlled drug delivery systems. Acta Poloniae Pharm Drug Res 2010;67:217-23.

15. Yogyata SP, Vishakha SH, Amruta NB. Polymers used for fast disintegrating oral films: a review. Int J Drug Sci Rev Res 2013;2129:169-78.

16. Teckoe J, Labriola A, Hansell J, Tom F. Stability study of PEG free, PVA based film coating system, AAPS; 2012. p. 1-4.

17. Sakellariou P, Rowe RC. Interactions in cellulose derivative films for oral drug delivery. Progress Polymer Sci 1995;20:889-942.

18. Banker GS. Film coating theory and practice. J Pharm Sci 1996;55:81-9. 